\title{
Dispersal modeling of fish early life stages: sensitivity with application to Atlantic cod in the western Gulf of Maine
}

\author{
Martin Huret $^{1,4, *}$, Jeffrey A. Runge ${ }^{2}$, Changsheng Chen ${ }^{1}$, Geoffrey Cowles ${ }^{1}$, \\ Qichun $\mathrm{Xu}^{1}{ }^{1}$ James M. Pringle ${ }^{3}$
${ }^{1}$ School of Marine Science and Technology, University of Massachusetts - Dartmouth, 706 South Rodney French Boulevard, New Bedford, Massachusetts 02744, USA
${ }^{2}$ Gulf of Maine Research Institute and School of Marine Sciences, University of Maine, 350 Commercial Street, Portland, Maine 04101, USA
${ }^{3}$ Coastal Observing Center and Ocean Process Analysis Laboratory, Institute for the Study of Earth, Oceans and Space, University of New Hampshire, 142 Morse Hall, Durham, New Hampshire 03824, USA

${ }^{4}$ Present address: IFREMER. Département Ecologie et Modèles pour l'Halieutique, BP21105, 44311 Nantes Cedex 03, France

\begin{abstract}
As an initial step in establishing mechanistic relationships between environmental variability and recruitment in Atlantic cod Gadhus morhua along the coast of the western Gulf of Maine, we assessed transport success of larvae from major spawning grounds to nursery areas with particle tracking using the unstructured grid model FVCOM (finite volume coastal ocean model). In coastal areas, dispersal of early planktonic life stages of fish and invertebrate species is highly dependent on the regional dynamics and its variability, which has to be captured by our models. With state-of-theart forcing for the year 1995, we evaluate the sensitivity of particle dispersal to the timing and location of spawning, the spatial and temporal resolution of the model, and the vertical mixing scheme. A $3 \mathrm{~d}$ frequency for the release of particles is necessary to capture the effect of the circulation variability into an averaged dispersal pattern of the spawning season. The analysis of sensitivity to model setup showed that a higher resolution mesh, tidal forcing, and current variability do not change the general pattern of connectivity, but do tend to increase within-site retention. Our results indicate strong downstream connectivity among spawning grounds and higher chances for successful transport from spawning areas closer to the coast. The model run for January egg release indicates 1 to $19 \%$ within-spawning ground retention of initial particles, which may be sufficient to sustain local populations. A systematic sensitivity analysis still needs to be conducted to determine the minimum mesh and forcing resolution that adequately resolves the complex dynamics of the western Gulf of Maine. Other sources of variability, i.e. large-scale upstream forcing and the biological environment, also need to be considered in future studies of the interannual variability in transport and survival of the early life stages of cod.
\end{abstract}

KEY WORDS: Gulf of Maine - Atlantic cod - Gadhus morhua - Larval transport · Particle dispersal · Modeling sensitivity $\cdot$ Spawning grounds $\cdot$ Meso-scale processes and turbulence

\section{INTRODUCTION}

Advances in modeling 3-dimensional circulation and hydrography in the ocean have stimulated application to understanding links between environmental variability and population dynamics of marine fish and invertebrate species. The ability to couple physical with biological understanding in model simulations provides insight into mechanisms by which climate influences recruitment processes (e.g. Cushing 1995, Runge et al. 2005) and spatial scales at which populations are connected via dispersal of larval stages (e.g. 
Cowen et al. 2000, 2006, Siegel et al. 2007), both of which are relevant to spatially explicit approaches to ecosystem-based fisheries management.

In the present paper, we initiate an investigation of the influence of physical transport processes on the dispersal of eggs and larvae of Atlantic cod Gadhus morhua in the western Gulf of Maine. While dispersal of the planktonic life stages of American lobster Homarus americanus in the Gulf of Maine has been studied using a coupled physical-biological model (Incze 2000), this approach has not yet been applied to cod in this region. The cod stock, which may comprise 3 or 4 sub-populations (Ames 2004), is overexploited and at historically low levels of biomass (Mayo et al. 1998). An understanding of processes controlling the dispersal of planktonic stages of cod from local spawning areas will lead to insight into the connectivity among sub-populations and their sources of larval supply.

As a first step, we describe here a particle-tracking approach using the finite volume coastal ocean model (FVCOM) to simulate dispersal from major spawning grounds of the western Gulf of Maine. The FVCOM simulates circulation and hydrography with realistic atmospheric and river input forcing, in this case, for the year 1995. We calculate a transport success defined as the proportion of starting eggs that subsequently develop as larvae and settle in nursery habitats associated with the Gulf of Maine sub-populations. We examine the sensitivity of the results to the way in which we configure the hydrodynamic model and set out the initial conditions. The biological behavior of individual particles (e.g. egg buoyancy, larval vertical

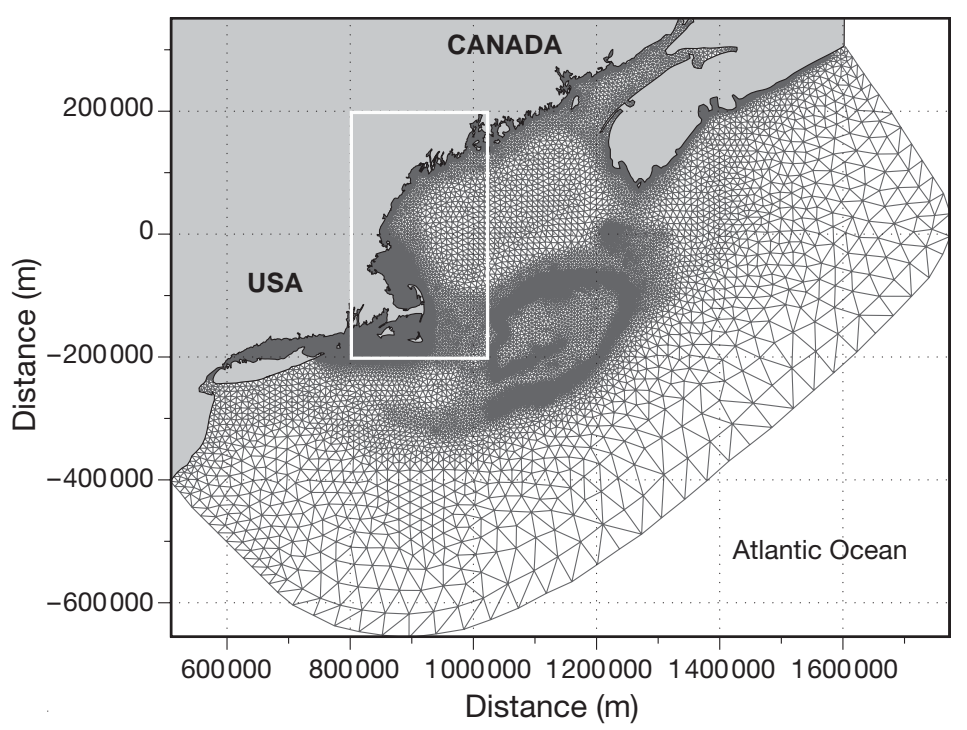

Fig. 1. FVCOM (finite volume coastal ocean model) grid for the Gulf of Maine area, showing location of the western Gulf of Maine study area (white box) described in Fig. 2 motion, trophodynamics) is not considered here; instead, we focus on the sensitivity of our index of transport success to: (1) spawning frequency and location, (2) mesh resolution and short time-scale variability of the velocity field, and (3) initial vertical distribution in relation to small-scale processes (i.e. turbulence). This sensitivity approach is a first step toward a systematic sensitivity analysis yielding the best model possible for the region, which should serve as a prerequisite to further ecological interpretation of the model output.

The Gulf of Maine (Fig. 1) has a general cyclonic circulation in which a coastal current flows southwestward along the coast of Maine (Brooks 1985) (Fig. 2). This Gulf of Maine Coastal Current (GMCC) consists of multiple branches (Lynch et al. 1997), with temporally variable connections between them (Pettigrew et al. 2005). The 2 major branches, the Eastern Maine Coastal Current (EMCC) and the Western Maine Coastal Current (WMCC), separate at the offshore veering of the EMCC in the vicinity of Penobscot Bay (Pettigrew et al. 2005). The core of the WMCC is centered over the $100 \mathrm{~m}$ isobath, where the current velocity ranges between 5 and $20 \mathrm{~cm} \mathrm{~s}^{-1}$ (Geyer et al. 2004, Churchill et al. 2005, Pettigrew et al. 2005). A freshwater plume adjacent to the coast, referred to as the Gulf of Maine Coastal Plume (GOMCP) by Keafer et al. (2005b), seasonally strengthens the southwestward flow (Geyer et al. 2004, Churchill et al. 2005).

Offspring from a given spawning location may be retained (Sinclair 1988), ultimately supporting local self-recruitment (Swearer et al. 2002), or be advected to a nursery area, after which surviving individuals either return to the original spawning area, contribute to spawning elsewhere, or are lost to the population's reproductive pool. Given the circulation in the western Gulf of Maine, it seems challenging for eggs and larvae to be retained locally, as compared, for example, with the anticyclonic circulation around Georges Bank (e.g. Lough et al. 2006). However, recent studies have shown the importance of the wind-driven modulation of the coastal flow in the western Gulf of Maine (Fong et al. 1997, Hetland \& Signell 2005), with eddies and meanders being able, at times, to dominate the near-shore current variance (Churchill et al. 2005). Bay trapping mechanisms may also help retention of particles, such as described for toxic algae in Casco Bay (Janzen et al. 2005, Keafer et al. 2005a). Massachusetts Bay may serve as another significant retention zone, with the branch of the WMCC entering it south of Cape Ann (Fig. 2). This complex and variable dynamic area is well suited as a test region for our sensitivity study. 


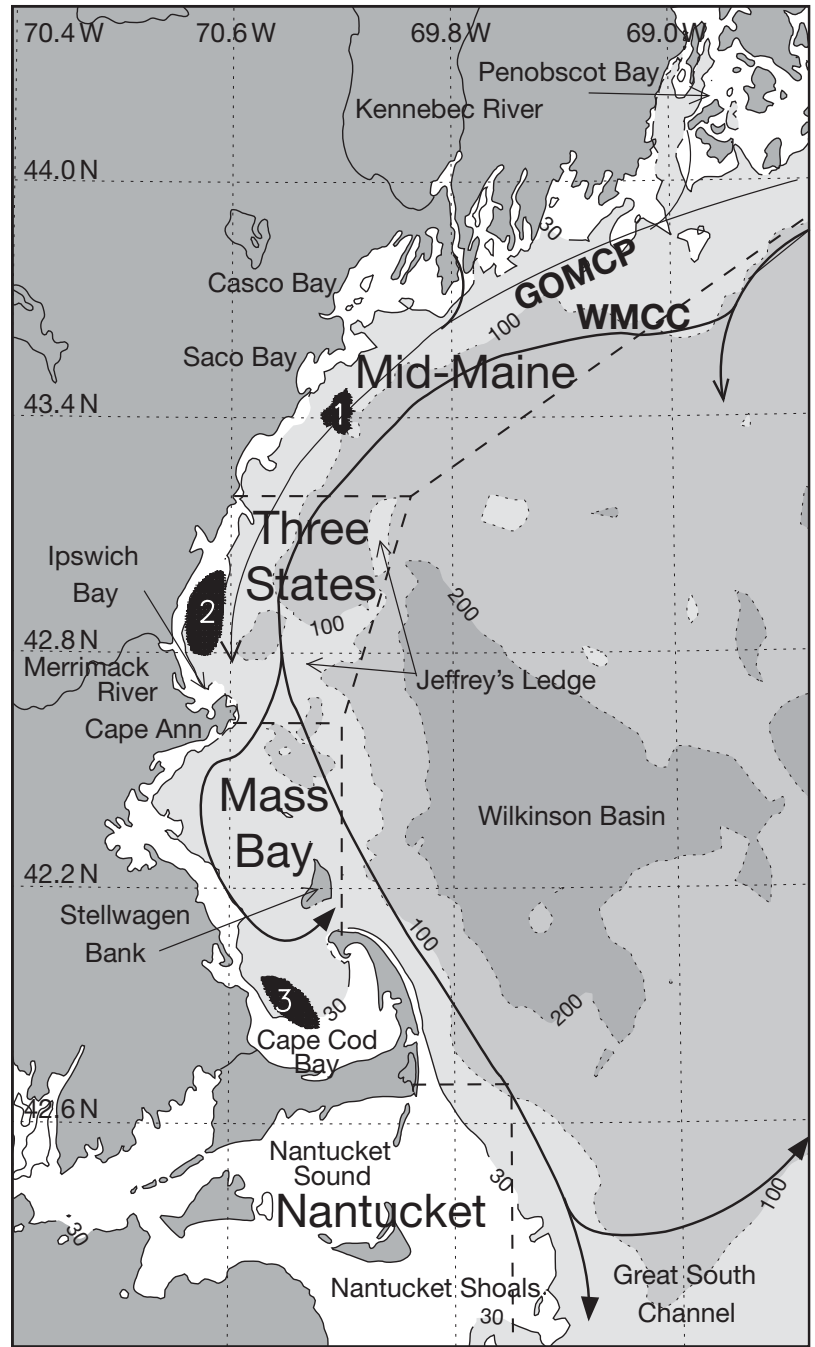

Fig. 2. Gadhus morhua. The 3 spawning ground locations (black) used in this study with the following names: Saco (1), Ipswich (2), and Cape Cod (3). Settlement areas are divided into 4 zones-Mid-Maine, Three States, Massachusetts (Mass.) Bay, and Nantucket-delimited by dashed lines. We define successful transport to juvenile settlement areas as the percentage of particles released that are found within the $30 \mathrm{~m}$ isobath during the last $15 \mathrm{~d}$ of their $2 \mathrm{mo}$ drift. The figure shows the main features of the near-surface coastal circulation (adapted from Lynch et al. 1997, Keafer et al. 2005b): the WMCC (Western Maine Coastal Current) and the GOMCP (Gulf of Maine Coastal Plume). Gray scale shows bathymetry

\section{METHODS}

Particle tracking. Lagrangian trajectories: Particle tracking is achieved by following Lagrangian trajectories using the FVCOM (Chen et al. 2003). This is an unstructured grid, finite-volume, free-surface, 3dimensional primitive equations model. It uses $\sigma$ coordinate transformation in the vertical to represent irregular bottom slope and surface elevation. It solves the governing equations in integral form by computing fluxes between non-overlapping horizontal triangular control volumes. This finite-volume approach combines the best of finite-element methods for geometric flexibility and finite-difference methods for computational efficiency. The ability of the FVCOM to fit irregular topography such as the coastal Gulf of Maine make FVCOM particularly suited for coastal ocean applications.

The grid covers the entire Gulf of Maine/Georges Bank region and is enclosed by an open boundary running from the New Jersey shelf to the Scotian Shelf (Fig. 1). Within the Gulf of Maine horizontal resolution ranges from 2 to $3 \mathrm{~km}$ in the basins to about $500 \mathrm{~m}$ in the coastal areas. There are 30 equally distributed Sigma layers vertically, for a vertical resolution of $3.3 \mathrm{~m}$ on the $40 \mathrm{~m}$ isobaths.

The model is driven by tidal forcing, which solves well the complex tidal dynamics of the Gulf of Maine, wind and heat fluxes from the fifth generation mesoscale meteorological model (MM5) hindcast at $10 \mathrm{~km}$ resolution (Chen et al. 2005), freshwater discharge from rivers, and upstream inflow condition on the Scotian Shelf. Daily mean sea surface temperature (SST) is nudged to satellite-derived SST. The model was run in this configuration for the year 1995, with a 1 mo spin-up starting from climatology density fields. This year is well suited for our study, since it is neither characterized by any particularly strong climatic events, nor by an extreme recruitment index.

In this work, we selected a Lagrangian method to describe particle transport, in anticipation of future refinement to include individual life histories, e.g. spatially varying growth rate and age-based behaviors, for which the Lagrangian approach is better adapted (Grimm 1999, Werner et al. 2001). Threedimensional Lagrangian pathways were calculated with model velocities saved every hour. The velocities were linearly interpolated in space and time, and a 120 s time step was used with an explicit fourth order Runge-Kutta scheme. Using saved model fields allowed us to run our analysis with large numbers of particles, which would have been prohibited by computer time otherwise. The high frequency at which output were saved from the FVCOM run prevents significant differences arising from the linear interpolation between the on-line and off-line particletracking methods.

Vertical random walk: A stochastic approach was added to the deterministic vertical transport of the particles. We used random walk to describe diffusion of particles. The calculation of random walk is based on the eddy diffusivity, calculated with the Mellor \& Yamada (1982) level 2.5 turbulent closure model, and also saved during the FVCOM runs. 
Following Visser (1997), we update the particle vertical location using the following equation:

$$
\begin{aligned}
& z_{(t+\delta t)}=z_{t}+w(t) \delta t+K^{\prime}\left(z_{t}\right) \delta t \\
& +R \sqrt{\frac{2 K\left(z_{t}+0.5 K^{\prime}\left(z_{t}\right) \delta t\right) \delta t}{\sigma^{2}}}
\end{aligned}
$$

with $z_{t}$ the vertical position of the particle at time $t, \delta t$ the time step, $w$ and diffusivity ( $K^{\prime}$, its first derivative) at the particle position, and $R$ the random variable with zero mean and standard deviation $\sigma$. In our case $R$ is a uniform deviate given by the Fortran 90 random number generator. Third and fourth terms on the right form the so-called 'random walk'. The former corresponds to a non-random 'advective' component, which was proposed by Visser (1997) to avoid erroneous particle accumulation in low-diffusivity areas. In the latter, the diffusivity is estimated at the particle location offset by a distance $0.5 K^{\prime}\left(z_{t}\right) \delta t$. In the range of the particle displacement, the diffusivity profile should be well approximated by the first-order Taylor expansion, which requires for the application of Eq. (1) that:

$$
\delta t \ll \min \left(1 /\left|K^{\prime \prime}\right|\right)
$$

with $K^{\prime \prime}$ the second derivate of the vertical diffusivity. This criterion was refined by Ross \& Sharples (2004), with some consideration of accumulation avoidance at the bottom and surface boundaries. They concluded that a time step $\delta t \simeq 1 / 100\left(1 /\left|K^{\prime \prime}\right|\right)$ is acceptable in most applications. Following Ross \& Sharples (2004), we also applied a cubic spline interpolation to the computed discrete diffusivity coefficient in order to obtain the necessary continuous and differentiable diffusivity profile. To respect the stability criterion at most locations and during most mixing events, the resulting time step for the random walk process is approximately $5 \mathrm{~s}$.

Description of dispersal. Location and timing of spawning: Bigelow \& Schroeder (1953) located cod Gadhus morhua spawning areas in the Gulf of Maine, with the most productive ones centered in Massachusetts Bay and just north of Cape Ann. Observations of the distribution and abundance of cod eggs (Berrien \& Sibunka 1999) indicate highest concentrations in the western Gulf of Maine in waters shallower than $100 \mathrm{~m}$ in the vicinity of Massachusetts Bay and Jeffrey's Ledge, consistent with the historic description by Bigelow \& Schroeder (1953). More recently, Ames (2004) identified 91 discrete historical spawning grounds from 1920s data and interviews with retired fishermen, in the coastal area from Cape Ann to Lurcher Shoal in the eastern Gulf of Maine. Nearly half of these spawning grounds would be abandoned today, with the disappearance of their spawning component from the stock. This identification, in conjunction with discussions with current local fishermen, helped us define major spawning sites still active in the west- ern Gulf of Maine, from which we released particles for our dispersal study (Fig. 2). For this study we included major historical locations in Ipswich Bay, north of Cape Ann, and Cape Cod Bay in the south of Massachusetts Bay, as well as spawning grounds offshore of Saco Bay in Maine, also identified by Ames (2004).

Timing and duration of the spawning season are difficult to assess for the Gulf of Maine cod subpopulations because of variability among and within spawning grounds, depending on environmental conditions (Lough 2004). Within the Gulf of Maine, cod have historically spawned throughout the winter and early spring at most locations, but the peak spawning varies depending on location (Schroeder 1930), with a general shift to later in the year for the more northerly regions. The range of spawning times combined with egg dispersal results in observations of a nearly year-round presence of eggs (Berrien \& Sibunka 1999). Nevertheless, periods of high spawning activity are distinguishable. Fish (1928) reported peak spawning activity during January and February for Massachusetts Bay. In some areas, peak spawning appears to be bi-modal. In and around Ipswich Bay, the largest spawning events occur in May/June, while a secondary period of peak activity occurs in December/ January (Wirgin et al. 2007). Based on this background information and our discussions with fishermen, we selected the following spawning periods for our 3 aggregated spawning grounds: (1) July and October for Saco Bay, (2) May to July and December/January for Ipswich Bay, and (3) December and January for Cape Cod Bay. Results presented below focus on January and July, which are both valid spawning periods for 2 of the selected spawning grounds. In each case, results for the third spawning location are also included.

Settlement areas: After a 2 to 3 mo drift in the water column, larval cod metamorphose into juveniles with settlement to the bottom shortly thereafter, at sizes of $<7 \mathrm{~cm}$ (Lough 2004). Based on analysis of multiyear trawl survey data of juvenile cod abundance off the Massachusetts coast, Howe et al. (2002) found the highest densities of newly settled cod nearshore at depths shallower than $30 \mathrm{~m}$ in spring and concluded that the region comprising Ipswich Bay, Massachusetts Bay, and Cape Cod Bay offered suitable habitat for successful settlement. The size criteria $(<10 \mathrm{~cm})$ of these Age-0 cod when compared with the size range of 2.5 to $7 \mathrm{~cm}$ at settlement (Lough 2004) confirms that they just settled, limiting the possibility that they have already migrated over large distances. Observations of early-stage juvenile abundance in other regions across the range of Atlantic cod corroborate the conclusion that settlement success of juvenile cod is higher in the shallow, nearshore habitat (Suthers \& Franks 1989, Dalley \& Anderson 1997). 
There is some evidence that juveniles do not exhibit any preference for substrate type at settlement (Howe et al. 2002), but subsequent spatial patterns are then altered by juvenile migration or habitat-specific post-settlement mortality (Tupper \& Boutilier 1995b). On Georges Bank, first settled juveniles are broadly distributed over the bank, but by late summer juveniles are mostly found on gravel bottom (Lough et al. 1989). In coastal Nova Scotia and Newfoundland, post-settlement survival and Age-0 abundance is highest in complex bottom types, i.e. sea-grass beds, cobble/gravel areas, and biogeniccovered rock reef (Tupper \& Boutilier 1995b, Grant \& Brown 1998). These observations correlate with a lower predation rate (including cannibalism) and a higher food availability in such complex habitats (Gotceitas \& Brown 1993, Gotceitas et al. 1995, Tupper \& Boutilier 1995a, Grant \& Brown 1998) than over fine-grain substrates (Tupper \& Boutilier 1995b).

All these complex bottom types are common in shallow waters of the western Gulf of Maine (Howe et al. 2002). While the U.S. Geological Survey sediment database for the east coast of the United States (Poppe et al. 2005) offers insight into possibly suitable habitats for cod juveniles, the resolution is still too coarse for fine-scale qualification of nearshore habitat. Thus, we define here suitable settlement areas as inshore areas within the $30 \mathrm{~m}$ isobath, without further consideration of habitat type.

Measuring transport success: Thousands of particles per spawning ground are released for each experiment (see values in Table 1), a necessary quantity to obtain stable results (i.e. same statistics for the particle distribution for independent runs). Particles are released every $5 \mathrm{~m}$ vertically, starting at $2.5 \mathrm{~m}$, and with a regular distribution horizontally in order to reach the stability defined above. Lacking an understanding of the factors that drive the timing of individual spawning events, we repeatedly released particles every $3 \mathrm{~d}$ during the prescribed spawning period, to simulate a series of successive spawning events. Three days corresponds to a typical decorrelation time-scale of the velocity field in coastal areas; therefore, particles released at this frequency should reflect the integrated seasonal transport variability at each spawning ground.
Hatching of Atlantic cod eggs occurs after 8 to $60 \mathrm{~d}$, depending on temperature, and larvae remain pelagic for about 3 mo (Lough 2004). With neither temperature dependence nor a trophodynamics model, a $60 \mathrm{~d}$ pelagic period was chosen here for investigation of egg and larval drift, as in comparable studies over Georges Bank (Werner et al. 1996, Lough et al. 2006) and in the Baltic Sea (Hinrichsen et al. 2001). While development time of all pelagic stages (i.e. eggs, larvae, and early juvenile) is likely to be longer, we assume that 2 mo is representative of the transport period. Indeed, vertical migration capacity and deepening in the water column contributes to retention of individuals in the deeper layers during the end of the pelagic stage (Lough \& Potter 1993), where weaker currents in the coastal Gulf of Maine tend to reduce the drift. This uncertainty on the drift duration could eventually be improved with a fully explicit model of the development of early life stages. The influence of the vertical behavior of larvae on our results is also further discussed in the 'Vertical distribution' section of the 'Discussion'.

We define an index of transport success for particles as the percentage of time they spend over suitable settlement areas in the last $15 \mathrm{~d}$ of their $60 \mathrm{~d}$ drift. The

Table 1. Connectivity matrices showing transport success (\%) of particles advected for $60 \mathrm{~d}$ with FVCOM (finite volume coastal ocean model) simulation of the circulation in the Gulf of Maine. For spawning grounds 1, 2, and 3 (see Fig. 2), transport success is averaged over successive releases at $3 \mathrm{~d}$ intervals throughout January 1995. Nominal: full-resolution simulation; coarse, filtered, and mean: model runs with different mesh and forcing resolutions, as discussed in 'Methods'. Relative error calculated as the percent difference in transport success between the nominal run and the coarse, filtered, or mean run, averaged over the 3 spawning grounds. n: number of particles. Mass.: Massachusetts

\begin{tabular}{|c|c|c|c|c|c|}
\hline \multirow{2}{*}{$\begin{array}{l}\text { Experiment } \\
\text { January }\end{array}$} & \multirow{2}{*}{ Success area } & \multicolumn{3}{|c|}{ Spawning ground } & \multirow{2}{*}{$\begin{array}{l}\text { Relative } \\
\text { error (\%) }\end{array}$} \\
\hline & & $1(\mathrm{n}=2735)$ & $2(\mathrm{n}=4040)$ & $3(\mathrm{n}=3675)$ & \\
\hline \multirow[t]{5}{*}{ Nominal } & Mid-Maine & 1.3 & 0.3 & 0.0 & \\
\hline & Three States & 1.1 & 2.4 & 0.0 & \\
\hline & Mass. Bay & 2.3 & 6.8 & 19.2 & \\
\hline & Nantucket & 5.6 & 8.2 & 13.9 & \\
\hline & All zones & 11.5 & 18.5 & 23.2 & \\
\hline \multirow[t]{5}{*}{ Coarse } & Mid-Maine & 0.5 & 0.0 & 0.0 & 54 \\
\hline & Three States & 1.1 & 0.7 & 0.0 & 24 \\
\hline & Mass. Bay & 1.7 & 3.9 & 13.2 & 33 \\
\hline & Nantucket & 9.4 & 13.9 & 23.6 & 69 \\
\hline & All zones & 12.7 & 18.5 & 36.8 & 45 \\
\hline \multirow[t]{5}{*}{ Filtered } & Mid-Maine & 1.1 & 0.4 & 0.0 & 16 \\
\hline & Three States & 1.0 & 2.3 & 0.0 & 5 \\
\hline & Mass. Bay & 1.8 & 4.4 & 11.9 & 32 \\
\hline & Nantucket & 2.7 & 4.7 & 8.8 & 44 \\
\hline & All zones & 6.6 & 11.8 & 20.7 & 24 \\
\hline \multirow[t]{5}{*}{ Mean } & Mid-Maine & 0.2 & 0.0 & 0.0 & 62 \\
\hline & Three States & 0.5 & 0.7 & 0.0 & 42 \\
\hline & Mass. Bay & 1.6 & 3.9 & 5.9 & 47 \\
\hline & Nantucket & 2.2 & 5.2 & 13.3 & 34 \\
\hline & All zones & 4.5 & 9.8 & 19.2 & 46.3 \\
\hline
\end{tabular}


transport success is then averaged over the number of particles per spawning ground, and, except for the first experiment on release frequency, over the successive releases within monthly periods.

The successful settlement areas are divided in 4 regions (see Fig. 2): (1) mid-Maine from Penobscot Bay to Saco Bay; (2) Three States, covering the New Hampshire coast, as well as part of the Massachusetts and Maine coasts; (3) Massachusetts and Cape Cod Bays; and (4) Nantucket Sound and Shoals. The transport success index is used in connectivity matrices between sources (spawning grounds) and sinks (settlement areas) of particles to show the relative dominance of either retention or downstream advection.

\section{RESULTS}

\section{Sensitivity to particle release}

\section{Release frequency}

We examined the effect of the release date within the peak spawning season of Atlantic cod Gadhus morhua on the dispersal of particles. Fig. 3 shows a time series of transport success in January 1995 based on successive releases at $3 \mathrm{~d}$ intervals. It reveals the potential for substantial (factor of 2) changes in transport success depending on release date, e.g. the change in success index from 25 to $14 \%$ in the Nantucket region between 4 and 7 January. The 1 mo spin-up before January should preclude any model adjustment as the cause of this rapid decrease, and we also observed changes of the same amplitude later in the year. These rapid changes, as well as more prolonged changes (e.g. the decrease of retention in Massachusetts Bay from spawning ground 3, between 16 and 28 January), need to be included to accurately represent the averaged transport success over the entire spawning period. A similar analysis for the month of July (not shown) indicates changes of lower magnitude between successive releases, a consequence of lower variation in wind forcing during summer months. This experiment shows that the choice of the release date may have strong influence on the success index, even for some release dates only separated by a few days. Given the high circulation variability, a dispersal descrip- tion from a unique release date is certainly not representative of the spawning period in a given year. In the following results, the 1 mo averaging period of successive $3 \mathrm{~d}$ releases gives robustness to the transport success patterns given a particular model configuration, and avoids erroneous conclusions that may result from interpretation of transport success from a single release date.

Release location

The area offshore of Saco Bay, including spawning ground 1 (Fig. 2), may comprise 3 discrete spawning grounds distributed in the cross-shore direction, according to fishermen. Whether there is a real spatial separation between them is unknown. However, there is likely interannual variability in the spawning location of a population at small scales, which may be represented by these 3 spawning grounds, and for which we can test the sensitivity of the dispersal of particles. Here, we investigate the transport of particles released in the 0 to 20 m layer, which allows consistent comparison between spawning grounds with different bathymetries. Fig. 4 shows an example of particle distribution after 1 mo of drift. Particles from the most offshore
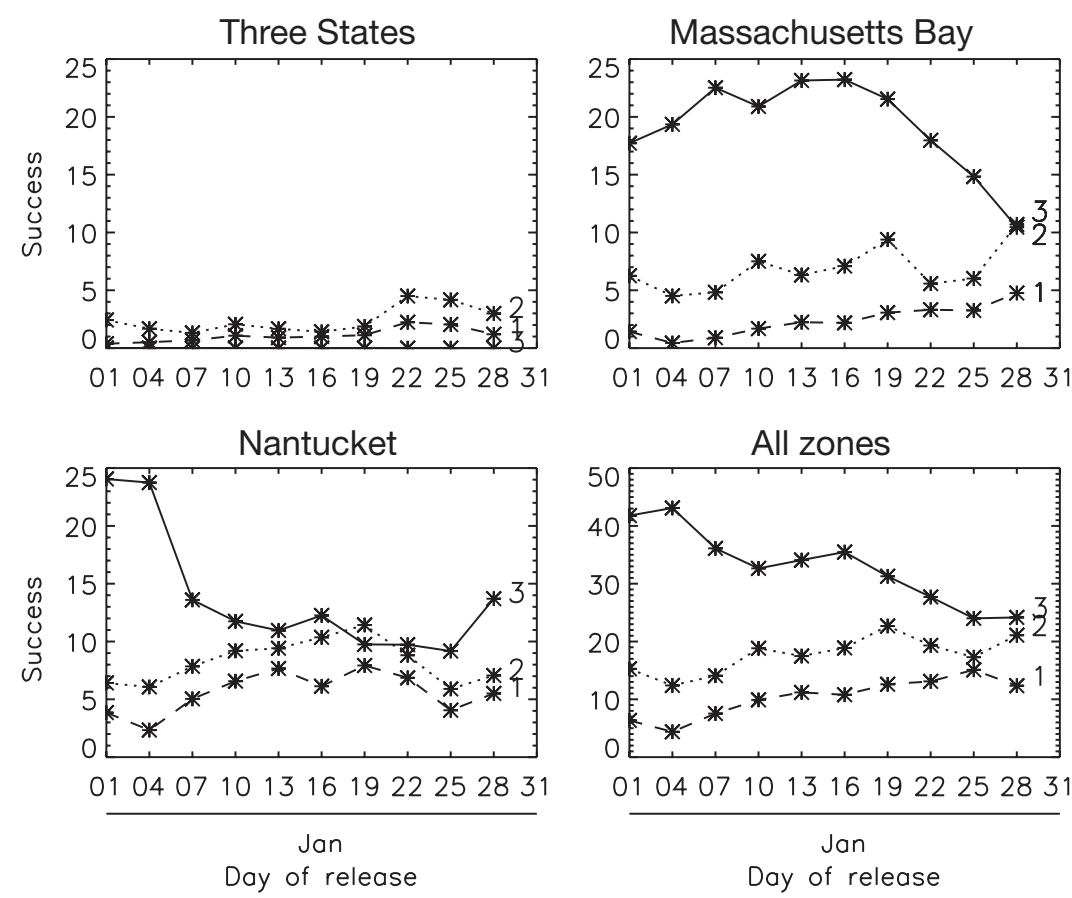

Fig. 3. Index of transport success (\%) to settlement areas depending on release date, based on FVCOM simulation. Releases are from spawning grounds $1(----), 2(\cdots \cdots)$, and $3(-)$ of Fig. 2. Mid-Maine settlement area not shown because transport success index is negligible relative to the other areas. The 'all zones' plot shows cumulative success over all settlement areas 
spawning ground are dispersed mostly offshore where they remain, whereas particles from the most inshore spawning ground are more likely to end up in coastal retention areas such as Massachusetts Bay. Fig. 5a shows, for all July 1995 releases, a transport success index decreasing from the inshore $(16 \%)$ to offshore (7\%) spawning ground. The $15 \mathrm{~km}$ separation between the 2 extreme locations cannot explain by itself such a difference. The main controlling factor is the location of the spawning ground in relation to the WMCC. The spawning ground furthest offshore (1c) is located at the core of the WMCC, which explains why fewer particles from this spawning ground were retained to the north in comparison with those of the 2 other areas ( $1 \mathrm{a}$ and $1 \mathrm{~b}$, see Fig. $5 \mathrm{~b}$ ), as well as the greater dispersal of its particles offshore.

\section{Circulation variability}

\section{Mesh resolution}

We compared the transport success using our original mesh with the results using a mesh with coarser resolution at some critical locations. These include inshore areas, which gives a lower resolution of coastline complexity (see Fig. 6), as well as Stellwagen Bank and Nantucket Sound, where an approximate $1 \mathrm{~km}$ mesh resolution substituted the original one at approximately $500 \mathrm{~m}$ (Fig. 6). The basin-scale circulation of the Gulf of Maine remained unchanged, allowing us to focus on the effects of local resolution difference.

Lack of coastline traps and mesoscale features, such as eddies over deeper areas around Stellwagen Bank (Fig. 7), increases downstream advection of particles (Fig. 8). The net result of reducing mesh resolution is a higher index of transport success for the most southern area (Nantucket) from all spawning grounds (see values in Table 1) and a decreased success in transport to the other defined settlement locations. Despite a larger number of particles advected from Spawning Areas 1 and 2, transport success is nevertheless also reduced in Massachusetts Bay. The unresolved eddies around Stellwagen Bank, which can be seen as deviation and retention processes into the bay, do not affect the particles that are instead carried away to the south by the WMCC.

\section{Temporal variability of the velocity field}

To assess the sensitivity of transport to changes in the model representation of the velocity field, we modified physical field outputs from the FVCOM in 2 separate simulations. In the first simulation, we used

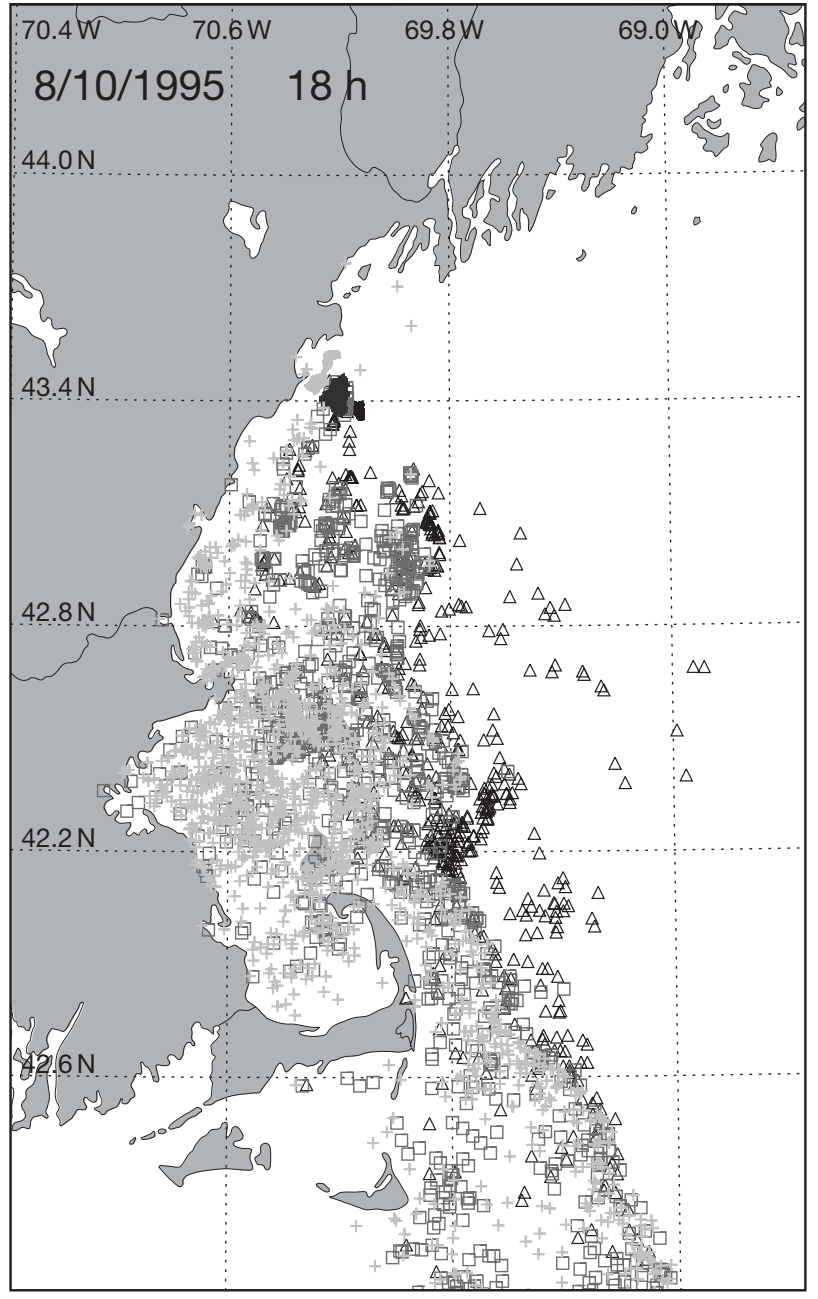

Fig. 4. Particle distribution after 1 mo of drift from Spawning Ground 1 (off Saco Bay), showing within-location variability in dispersal of release in the surface layer on 10 July with random walk. Light gray +: inshore spawning area; dark gray open square: middle spawning area as in Fig. 2; and black open triangle: offshore spawning area

a low-pass filter to remove the tidal high-frequency component, keeping only the tidal residual. In the second simulation, we replaced the high-frequency velocity field output from the FVCOM with a monthly average.

Differences in transport success between simulations using the original FVCOM output and with the high frequency of the tide removed are not noticeable (see Fig. 9a,b as an example; see also Fig. 10a,b, Table 1). Exceptions are south of Cape Cod, where fewer particles can reach Nantucket Sound and Shoals, a region with strong and complex tidal currents (e.g. Shearman \& Lentz 2004), and in Massachusetts Bay, where tidal current variability may enhance inward transport of particles into the bay and entrapment in its embayments. 

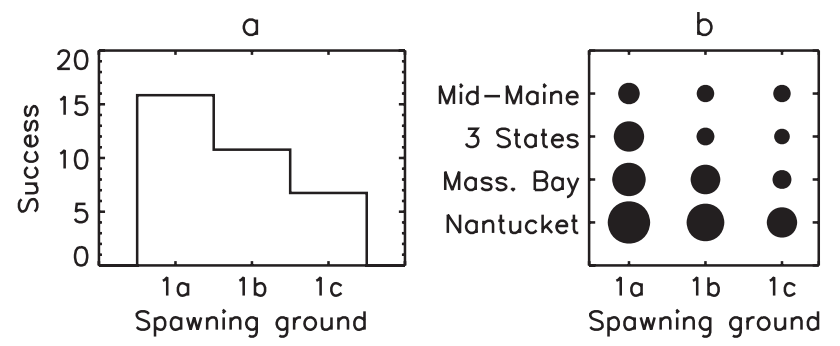

Fig. 5. Index of transport success (\%) for July releases at the 3 discrete areas of Spawning Ground 1 (1a: light-gray inshore location of Fig. 4; 1b: dark-gray location; 1c: offshore black location): (a) integrated over all 4 success areas, (b) transport success between each spawning location and settlement area (connectivity matrix). Circle surface area is proportional to the magnitude of transport success. Mass.: Massachusetts
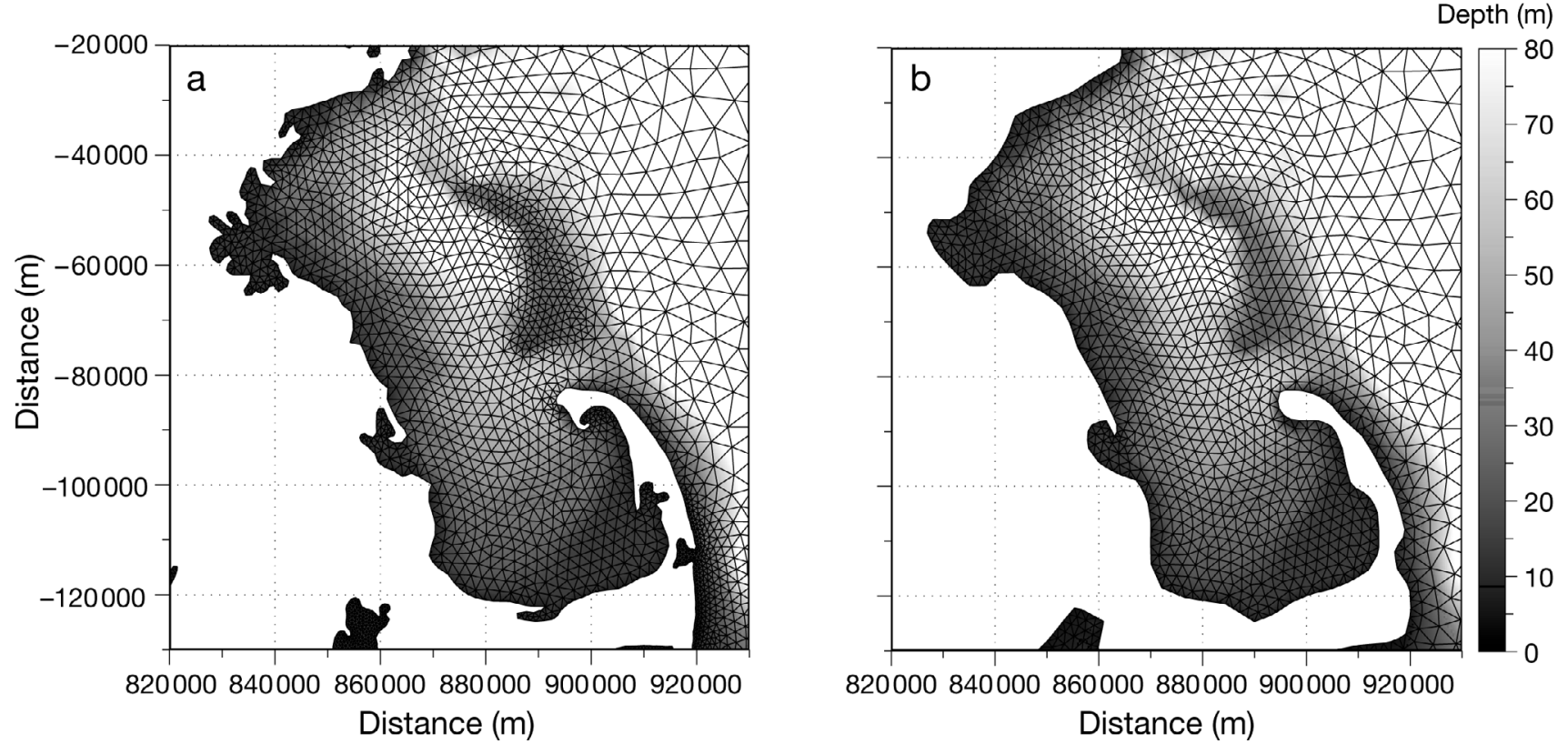

Fig. 6. (a) High and (b) low resolution mesh in the vicinity of Massachusetts Bay. Differences in mesh resolution occur over Stellwagen Bank and along the coast
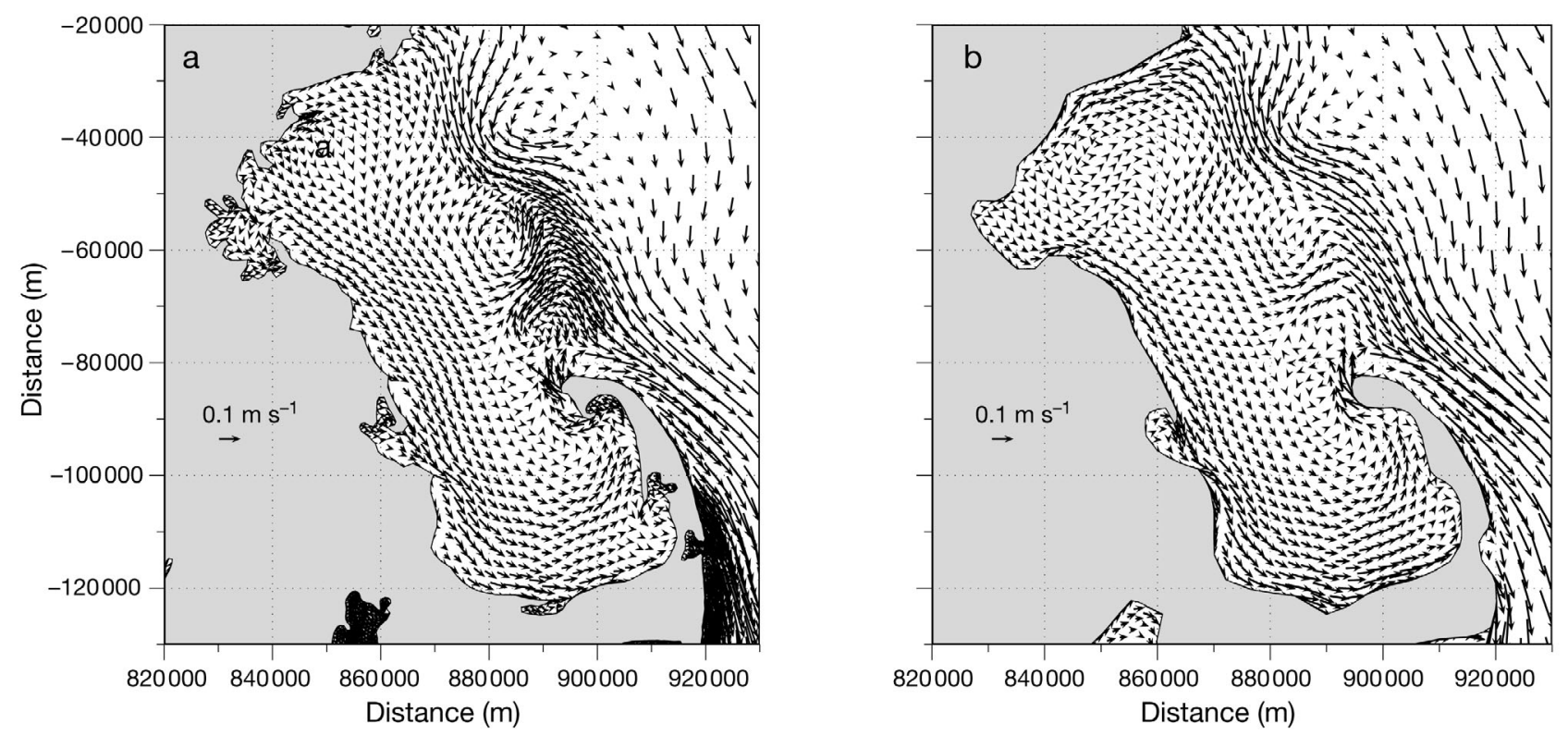

Fig. 7. Surface monthly mean (February 1995) current for (a) high and (b) low mesh resolution in Massachusetts Bay. Residual eddies to the west and northeast of Stellwagen Bank, which appear in the high-resolution simulation, are not resolved using the coarser mesh 

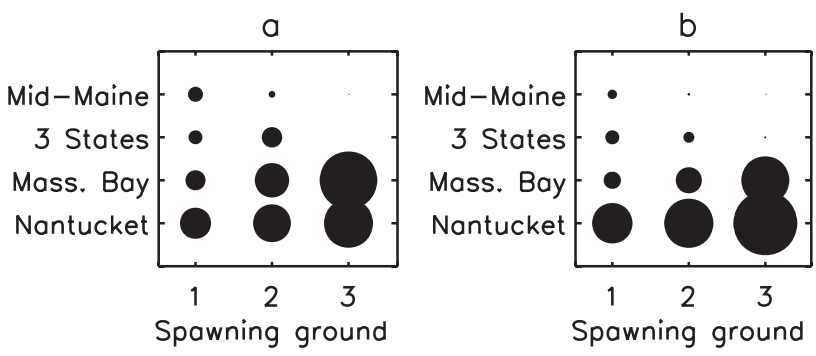

Fig. 8. Connectivity matrices (as in Fig. 5b) for (a) high and (b) low mesh resolution based on releases in January 1995. Circle surface area is proportional to the magnitude of transport success. Actual values of transport success and relative error with respect to the high-resolution run are given in Table 1. Mass.: Massachusetts

Application of a monthly mean velocity field leads to strong downstream advection, with only few particles entering and ending up in Cape Cod Bay and inshore Massachusetts Bay (Fig. 9c). Differences from the original simulation are notable everywhere (Fig. 10c, Table 1). Very few particles are retained in the coastal areas in the north, due to strong downstream advection, but the success indexes are also lower in Massachusetts Bay and around Nantucket for spawning grounds 1 and 2. Lack of variability in the circulation lessens transport toward the coastal nursery areas of particles advected downstream. Nevertheless, for spawning ground 3 this effect is attenuated by larger number of particles advected from Cape Cod Bay that sustain the success level in the downstream region of Nantucket as compared with the nominal run.

\section{Turbulence and vertical distribution}

In this sensitivity experiment, we investigated particle dispersal without random walk. In this case, vertical movement depends only on the weak vertical advection, and, consequently, most particles remain at their release depth. The first example examines release of particles in January 1995, during mixed conditions in winter. In the second example, particles are released in July 1995, representing summer conditions, with strong stratification in the $15 \mathrm{~m}$ surface layer.

In the winter, cumulative transport success (Fig. 11) is sensitive to application of random walk. With the use of random walk and for spawning grounds 1 and 3, transport success is almost uniform for releases made over the whole water column, as vertical mixing quickly redistributes particles. Without application of random walk, there is a success gradient from the surface to the bottom for the 3 spawning grounds: particles mostly remain at their initial depth and are consequently advected by different currents. For spawning ground 2, the proximity of the mouth of the Merrimack River creates low stratification, which possibly decouples surface and bottom transport of particles, even in the case with random walk.
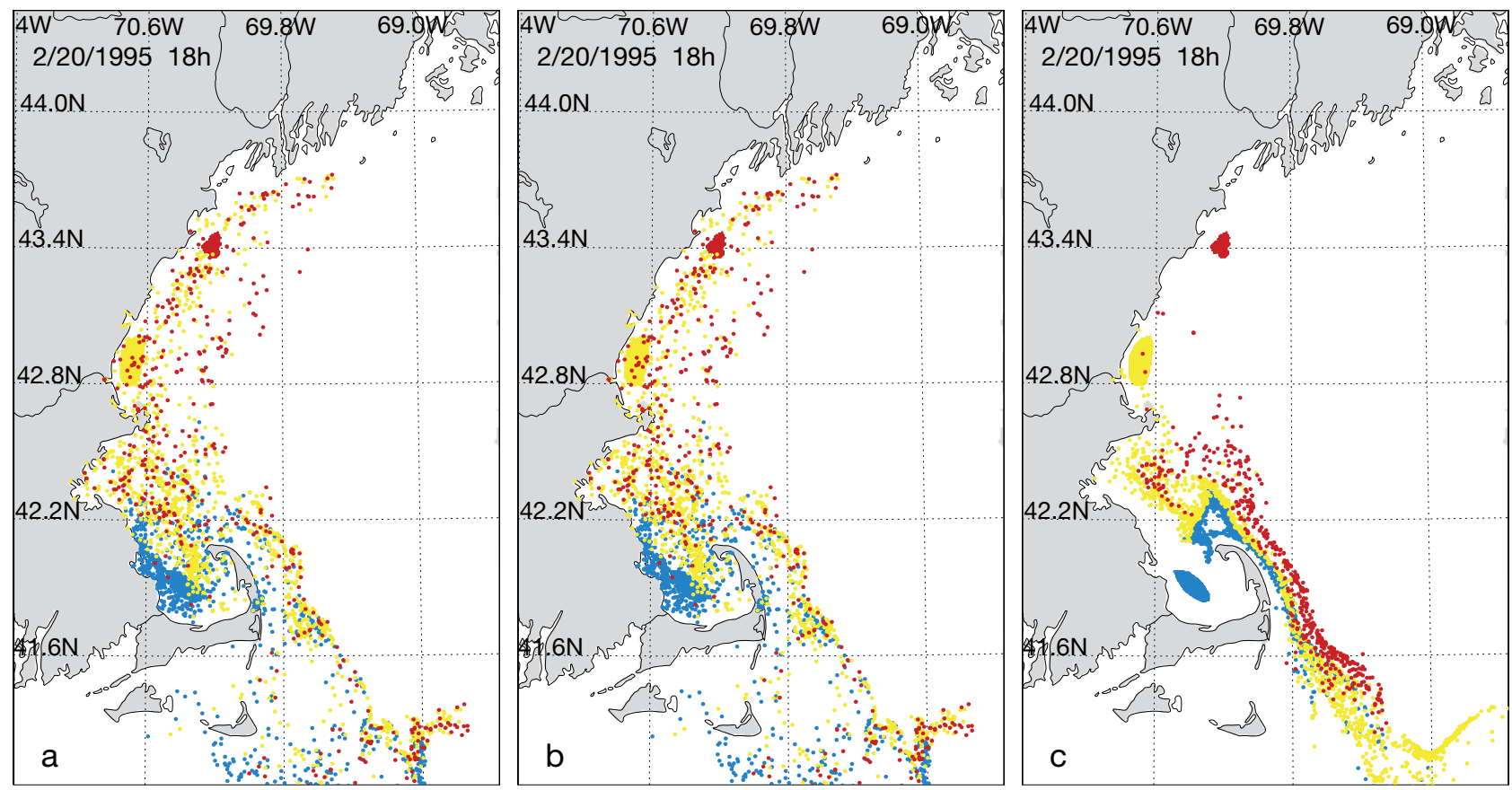

Fig. 9. Particle distributions after 1 mo drift with random walk starting on 20 January 1995. Spawning grounds, best seen in Panel c, (and distributions) are color coded (1: red; 2: yellow; 3: blue). Particle tracks are from (a) nominal, (b) low-pass-filtered, and (c) monthly averages of the physical field 

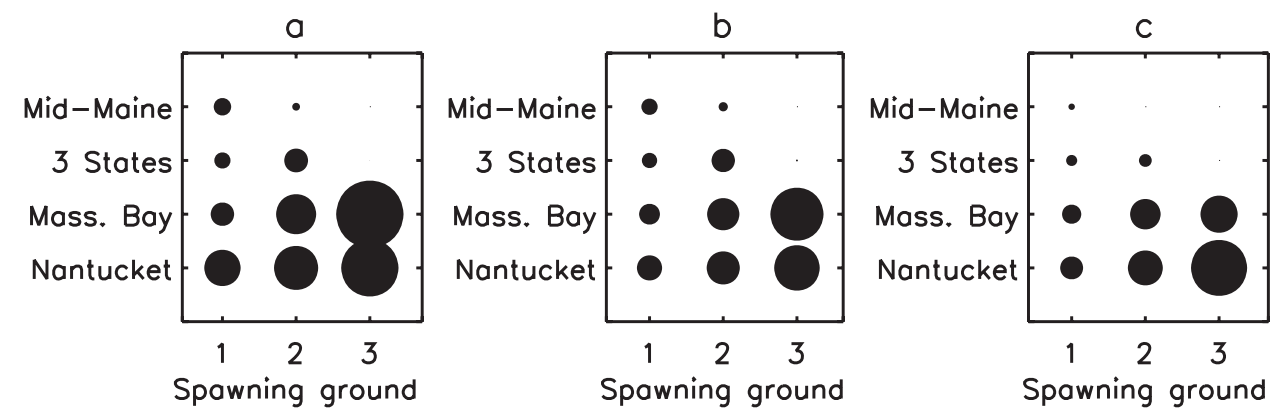

Fig. 10. Connectivity matrices for transport success for releases in January 1995, shown in Fig. 9. (a) Nominal run, (b) low-pass filtering of physical fields, and (c) monthly mean physical fields. Circle surface area is proportional to the magnitude of transport success. Actual values of transport success and relative error with respect to the nominal run are given in Table 1. Mass.: Massachusetts

In summer, there is no significant difference between presence or absence of random walk, due to low mixing (except in a thin surface mixed layer for spawning ground 1 and on the bottom layer of spawning ground 3) (Fig. 12). We observe that depending on the spawning ground and associated local 3-dimensional circulation, larvae are more likely to be successful if particles are released between 20 and $40 \mathrm{~m}$ (spawning ground 1), at the surface (spawning ground 2), or at the bottom (spawning ground 3). Further investigation needs to address whether or not release depth for maximum withinarea transport success is the same as the depth for maximum overall transport success.
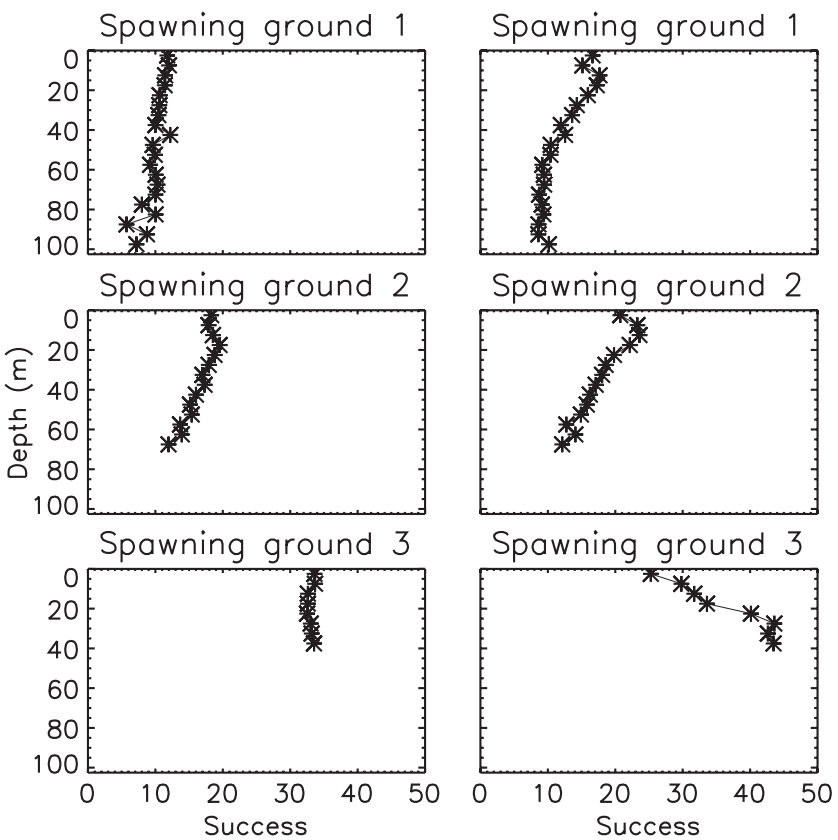

Fig. 11. Index of overall transport success (\%) as a function of release depth for particles from the 3 spawning grounds shown in Fig. 2: January 1995 simulation. Left panels: subject to random walk; right panels: not subject to random walk

\section{DISCUSSION}

\section{Characterizing location and timing of larval release}

Our analysis shows that transport success is dependent on the spawning date of Atlantic cod Gadhus morhua, reflecting the daily variability in wind and circulation velocities that impart a unique cumulative transport history to each particle release. We assumed that release every $3 \mathrm{~d}$ is more representative of the protracted period of cod spawning, which may be an adaptive mechanism to increase retention probability and local recruitment success (Byers \& Pringle 2006) by integrating over seasonal climate variability. How-
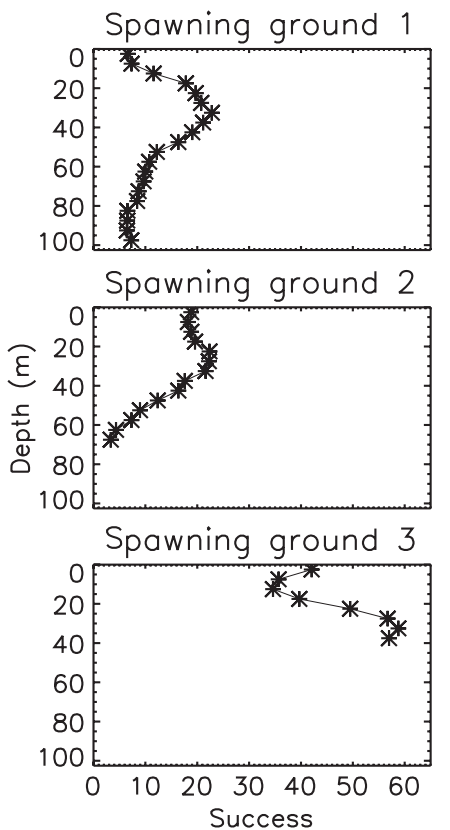

Fig. 12. Index of overall transport success (\%) as a function of release depth for particles from the 3 spawning grounds shown in Fig. 2: July 1995 simulation. Left panels: subject to random walk; right panels: not subject to random walk 
ever, if spawning release is more episodic, a better understanding of the fine-scale timing of spawning events in relation to the changing environment is needed for more accurate assessment of dispersal in any given year.

Through discussions with knowledgeable local fishermen, we refined the location of spawning areas. Differences in transport success under identical conditions from adjacent spawning areas off Saco Bay indicate a need for accurate fine-scale descriptions of spawning areas. For example, in Ipswich Bay, local fishermen can locate $>15$ separate spawning sites (H. Howell, UNH, pers. comm.). This micro-scale site selection by spawning cod, potentially related to bottom topography associated to meso-scale structures, may impact the dispersal of pelagic stages, perhaps enhancing within-site retention.

\section{The model setup}

Results from the analysis of sensitivity to the model setup showed that changes to mesh resolution and to representation of short-time-scale current fields impacts within-site retention, although the general pattern of connectivity remains intact. Relative errors in terms of connectivity matrix values range between $24 \%$, for the tidally filtered run, to about $45 \%$, in runs using a lower resolution or mean current fields (Table 1). These relative errors are also significant, looking at each success area, even if absolute transport success may be an order of magnitude different between them. This supports our interpretation of sensitivity results for all our defined sub-regions of the western Gulf of Maine.

The strong change induced when only slightly modifying the mesh resolution suggests caution when interpreting results of particle dispersal from model runs with a low-resolution grid in coastal areas. We showed that a resolution even as high as $1 \mathrm{~km}$ may not be sufficient to resolve eddies in some critical locations; with the FVCOM irregular grid we were able to match the complex coastline and better resolve the meso-scale circulation by increasing the resolution where necessary.

In particle-tracking studies, time computing or data storage issues have often imposed the use of residual currents, or large time steps that remove the high frequency of tide. With these model configurations, our results showed that in coastal regions with high tidal energy, the retention at spawning sites or trapping of particles in settlement areas can be decreased. The small time step we used here, consistent with the internal time step of our FVCOM run, resolves the tide. Tracking particles with monthly mean averages of the velocity fields removes another level of short-timescale variability (i.e. the variability due to the wind or the non-linearities in the model itself), and the dispersal patterns are highly modified as a consequence.

Our result highlights the limitations of interpreting dispersal patterns from such model configurations, and the requirements for small space- and time-scale model resolution. The current model, although it operates with state-of-the art grid and forcing resolution, may still not resolve correctly the retention processes and, consequently, may underestimate the potential for within-area retention (Swearer et al. 2002). Further validation of the hydrodynamics, including analysis to determine under what mesh resolution the connectivity matrices become stable, should clarify this uncertainty. This would also give insight on the resolved horizontal variability by the model, and the possible requirement of some additional horizontal random walk for sub-grid-scale processes.

\section{Vertical distribution}

Our vertical distribution experiments showed that for passive particles, vertical mixing is an important factor in highly diffusive environments (e.g. winter or high tidal mixing areas). In these cases, initial vertical distribution of particles does not have much influence on their final location, since all particles are rapidly stirred over the whole water column. However, in stratified environments, initial vertical distribution of particle release is critical in determining the final distribution.

Our results are valid for passive particles such as eggs and recently hatched larvae, for the most part during the first month of drift. Older larvae acquire a swimming capacity allowing them to migrate daily within the water column, even though average residence depth deepens proportionally with their age (e.g. Lough \& Potter 1993). Progressive loss of sensitivity to the turbulent field is likely to come with this swimming capacity (Ross \& Sharples 2004), making random walk inappropriate. Since we showed that vertical distribution might be critical in the transport, particle dispersal may be modified during the second month of drift, in the direction of more retention. A complementary sensitivity analysis of this biological behavior, as well as the influence of horizontal swimming on dispersal, needs to be conducted.

Egg and early larval buoyancy were not considered in our experiments. In stratified waters, buoyancy will rapidly drive the particles to the surface, in which case realistic dispersal should be based on surface releases, unless explicit modeling of the buoyancy is added with respect to the density field. Buoyancy is likely 
to increase the downstream advection of particles by strong surface currents, which can be counterbalanced by stronger dispersal in different directions influenced by wind. Here, density difference with the surrounding fluid may modify the response to the turbulent field (Ross \& Sharples 2004). However, observations in well mixed waters over Georges Bank (Lough \& Potter 1993) reveal a homogeneous egg distribution throughout the water column, supporting our use of random walk for the egg stage.

\section{Preliminary ecological implications}

A single year (1995) cannot be used to deduce representative, climatological dispersal patterns. Results from runs simulating different years, to study the interannual variability, or to build the mean connectivity matrix among sites, will yield more stable patterns of the dispersal in this region. The model results nevertheless suggest several ecological implications for understanding the spawning patterns in the western Gulf of Maine. First, there is a higher chance for successful transport to juvenile nursery areas within the Gulf of Maine if spawning occurs inshore, even in the presence of cross-shore transport due to local variability. Second, different experiments converge to indicate that overall transport success is highest for spawning ground 3 of Cape Cod Bay, followed by Ipswich Bay, and then the spawning ground off Saco Bay. This overall gradient in transport success is attributed to the differences in self retention among zones. Massachusetts and Cape Cod bays are relatively less affected by downstream advection as compared to Ipswich Bay or the very exposed spawning ground off Saco Bay. Evidence from cod stocks across the North Atlantic attributes increasing importance to near-shore spawning and nursery areas (Hutchings et al. 1993). Nearshore spawning and mechanisms for cross-shelf transport (including tide and factors of variation of the coastal current at short time scales) appear to be very important determinants of juvenile membership in the Gulf of Maine populations. Hence, variability in these mechanisms has great potential to be a primary determinant of recruitment success.

In all cases, our model results show that spawning sites are very connected to juvenile nursery areas downstream. Conversely, there is very little upstream connectivity, regardless of initial conditions. There is considerable mixing of juveniles originating from different spawning sites in Ipswich Bay and especially in Massachusetts and Cape Cod bays. Such mixing would not promote small-scale population distinctness. Juveniles in the mixed nursery areas may return to their original spawning ground to spawn as adults, join the sub-population native to the spawning ground closest to the nursery area, or form a transient population that migrates to spawning sites that may or may not be the same as those identified here, without a predetermined affinity for any particular site. This may be the case for far-exported vagrants to Nantucket Sound and Shoals or to Georges Bank, unless such a distance precludes survivorship of larvae or juveniles. Modeling work, in connection with other modern methodologies such as DNA studies (e.g. Wirgin et al. 2007) or chemical tracking, should help to answer these questions.

Given the overall downstream pattern of dispersal, the challenge for the cod stock and sub-populations in the western Gulf of Maine is how to maintain local populations. We examined this question in more detail looking at the within-site transport success. Our nominal January runs yield 1.3 to $19.2 \%$ retention of the number of particles originally released over a $60 \mathrm{~d}$ planktonic phase (Table 1). Assuming a low value of $2 \%$ for this retention and a mortality rate of $0.08 \mathrm{~d}^{-1}$ (Houde 1988), approximately 60 Age-0 cod would be retained in local nursery areas from the production of 375000 eggs, the average egg production by a $50 \mathrm{~cm}$ female (Collette \& Klein-MacPhee 2002). The number of surviving juveniles from the average egg output is highly dependent on the daily mortality rate, which would vary depending on the predator and prey fields in the environment. Nevertheless, our model results indicate the potential for prolific spawners such as cod to maintain local populations along the coast of the western Gulf of Maine.

\section{CONCLUDING REMARKS}

In the western Gulf of Maine, like in other North Atlantic regions, many interacting physical and biological factors may explain the variability observed in cod recruitment. Along-shore circulation, associated with a complex topography, defines the basic pattern of the connectivity matrix between spawning and settlement areas. Local forcing variability (river discharge, wind) may explain part of the recruitment variability by modulating the circulation. In addition, upstream, largescale forcing (i.e. Scotian Shelf inflow) and density of waters entering the gulf are likely to play an important role in controlling coastal Gulf of Maine circulation variability (Pringle 2006). Our study addresses the sensitivity of the dispersal of particles to model skill at representing some of this physical variability. Further validation is necessary to obtain the minimum model requirements that would correctly resolve the dynamics involved in passive transport of particles. As these requirements depend on the circulation and topographical features specific to each coastal area, we 
suggest that a search for adequate model configuration should be conducted in each regional study. Then, for a fully explicit early life history, biological processes including food limitation and predation on larval growth and mortality could be studied as additional sources of variability in cod recruitment.

The Gulf of Maine cod stock is managed separately from the nearby cod stocks inhabiting the offshore banks on the Scotian Shelf and Georges Bank (O'Brien et al. 2005). There is, however, a high potential for export out of the coastal Gulf of Maine region, to Nantucket Sound and Shoals or beyond and to Georges Bank. The question of whether juveniles finding themselves in these potential nursery grounds are still connected to western Gulf of Maine stocks, or whether they are vagrants lost to the reproductive pool of any NW Atlantic sub-populations is still to be resolved. Recent studies are moving toward application of smaller scale, spatially explicit management approaches. The population structure in the Gulf of Maine likely conforms to a meta-population, in which each sub-population gathers several spawning components (Ames 2004). The diversity and richness of this structure may need to be accounted for in a successful long-term strategy for conservation of local populations. The coupled physical-biological model will be useful for evaluating the sensitivity of sub-populations to environmental variability, as well as for understanding the long-term trends in contribution and selection of the spatially explicit spawning components.

Acknowledgements. We thank R. Ji for useful discussions and comments on the particle-tracking code. We gratefully acknowledge R. Gauron, D. Goethel, G. Littlefield, F. Mirarchi, C. Pendleton, P. Taylor, and N. Vine for discussions of spawning locations, and Amy Holt Cline for mapping the experiential knowledge of the pre-cited fishermen. We thank the 3 anonymous reviewers for their useful and constructive comments, as well as A. Gallego, E. North, and P. Petitgas, the 3 co-editors of this group submission and co-chairs of the 'Workshop on advancements in modelling physical-biological interactions in fish early-life history: recommended practices and future directions'. This research was funded by the Coastal Observing Center (UNH) through grants from the NOAA Coastal Services Center, and the NSF/NOAA US GLOBEC Northwest Atlantic/Georges Bank program.

\section{LITERATURE CITED}

Ames E (2004) Atlantic cod stock structure in the Gulf of Maine. Fish Res 29:10-28

Berrien P, Sibunka J (1999) Distribution patterns of fish eggs in the U.S. Northeast continental shelf ecosystem, 1977-1987. NOAA Tech Rep 145:1-310

Bigelow H, Schroeder W (1953) Fishes of the Gulf of Maine. Fish Bull 53:1-577

Brooks D (1985) Vernal circulation in the Gulf of Maine. J Geophy Res 90:4687-4705

Byers JE, Pringle JM (2006) Going against the flow: retention, range limits and invasions in advective environments. Mar Ecol Prog Ser 313:27-41

Chen C, Liu H, Beardsley R (2003) An unstructured grid, finite-volume, three-dimensional, primitive equations ocean model: application to coastal ocean and estuaries. J Atmos Ocean Technol 20:159-186

Chen C, Beardsley R, Hu S, Xu Q, Lin H (2005) Using MM5 to hindcast the ocean surface forcing fields over the Gulf of Maine and Georges Bank region. J Atmos Ocean Technol 22:131-145

Churchill J, Pettigrew N, Signell R (2005) Structure and variability of the Western Maine Coastal Current. Deep-Sea Res II 52:2392-2410

Collette B, Klein-MacPhee G (eds) (2002) Bigelow and Schroeder's fishes of the Gulf of Maine. Smithsonian Institution Press, Washington, DC

Cowen R, Lwiza K, Sponaugle S, Paris C, Olson D (2000) Connectivity of marine populations: open or closed? Science 287:857-859

Cowen R, Paris C, Srinivasan A (2006) Scaling of connectivity in marine populations. Science 311:522-527

Cushing D (1995) Population production and regulation in the sea: a fisheries perspective. Cambridge University Press, Cambridge

Dalley E, Anderson J (1997) Age-dependent distribution of demersal juvenile Atlantic cod (Gadus morhua) in inshore/ offshore northeast Newfoundland. Can J Fish Aquat Sci 54(Suppl 1):168-176

Fish C (1928) Production and distribution of cod eggs in Massachusetts Bay in 1924 and 1925. Bull US Bur Fish 43: 253-296

Fong D, Geyer W, Signell R (1997) The wind forced response on a buoyant coastal current: observations of the western Gulf of Maine plume. J Mar Syst 12:69-81

Geyer W, Signell R, Fong D, Wang J, Anderson D, Keafer B (2004) The freshwater transport and dynamics of the western Maine coastal current. Cont Shelf Res 24:1339-1357

Gotceitas V, Brown J (1993) Substrate selection by juvenile Atlantic cod (Gadus morhua): effects of predation risk. Oecologia 93:31-37

Gotceitas V, Fraser S, Brown J (1995) Substrate selection by juvenile Atlantic cod in the presence of an actively foraging and non-foraging predator. Mar Biol 123:421-430

Grant S, Brown J (1998) Nearshore settlement and localized populations of age 0 Atlantic cod (Gadus morhua) in shallow coastal waters of Newfoundland. Can J Fish Aquat Sci 55:1317-1327

Grimm V (1999) Ten years of individual-based modelling in ecology: What have we learned and what could we learn in the future? Ecol Model 115:129-148

Hetland R, Signell R (2005) Modeling coastal current transport in the Gulf of Maine. Deep-Sea Res II 52:2430-2449

Hinrichsen HH, St. John M, Aro E, Gronkjaer P, Voss R (2001) Testing the larval drift hypothesis in the Baltic Sea: retention versus dispersion caused by wind-driven circulation. ICES J Mar Sci 58:973-984

Houde E (1988) Fish early life dynamics and recruitment variability. Am Fish Soc Symp 2:17-29

Howe A, Correia S, Currier T, King J, Johnston R (2002) Spatial distribution of ages 0 and 1 Atlantic cod (Gadus morhua) off the eastern Massachusetts coast, 1978-1999, relative to 'Habitat Area of Special Concern'. Technical Report 12, Massachusetts Division of Marine Fisheries, Pocasset, MA

Hutchings J, Mayers R, Lily G (1993) Geographic variation in the spawning of Atlantic cod, Gadus morhua, in the Northwest Atlantic. Can J Fish Aquat Sci 50:2457-2467 
Incze L (2000) Modelling the transport of lobster (Homarus americanus) larvae and postlarvae in the Gulf of Maine. Fish Oceanogr 9:99-113

Janzen C, Churchill J, Pettigrew N (2005) Observations of exchange between eastern Casco Bay and the western Gulf of Maine. Deep-Sea Res II 52:2411-2429

Keafer B, Churchill J, Anderson D (2005a) Blooms of the toxic dinoflagellate, Alexandrium fundyense in the Casco Bay region of the western Gulf of Maine: advection from offshore source population and interaction with the Kennebec River plume. Deep-Sea Res II 52:2631-2655

Keafer B, Churchill J, McGillicuddy D, Anderson D (2005b) Bloom development and transport of toxic Alexandrium fundyense populations within a coastal plume in the Gulf of Maine. Deep-Sea Res II 52:2674-2697

Lough RG (2004) Essential fish habitat source document: Atlantic cod, Gadus morhua, life history and habitat characteristics, 2nd edn. NOAA Tech Memo NMFS-NE190, NOAA-NMFS, Woods Hole, MA

Lough RG, Potter DC (1993) Vertical distribution patterns and diel migrations of larval and juvenile haddock Melanogrammus aeglefinus and Atlantic cod Gadus morhua on Georges Bank. Fish Bull 91:281-303

Lough RG, Valentine PC, Potter DC, Auditore PJ, Bolz GR, Neilson JD, Perry RI (1989) Ecology and distribution of juvenile cod and haddock in relation to sediment type and bottom currents on eastern Georges Bank. Mar Ecol Prog Ser 56:1-12

Lough RG, Hannah CG, Berrien P, Brickman D, Loder JW, Quinlan JA (2006) Spawning pattern variability and its effect on retention, larval growth and recruitment in Georges Bank cod and haddock. Mar Ecol Prog Ser 310: $193-212$

Lynch D, Holboke M, Naimie C (1997) The Maine coastal current: spring climatological circulation. Cont Shelf Res 17:605-634

Mayo R, O'Brien L, Wigley S (1998) Assessment of the Gulf of Maine Atlantic cod stock for 1998. Ref. Doc. 98-13, Northeast Fisheries Science Center, Woods Hole, MA

Mellor G, Yamada T (1982) Development of a turbulence closure model for geophysical fluid problem. Rev Geophys Space Phys 20:851-875

O'Brien L, Lough R, Mayo R, Hunt J (2005) Gulf of Maine and Georges Bank (NAFO Subareas 5 and 6). In: Brander K (ed) Spawning and life history information for North Atlantic cod stocks, No. 274. ICES Cooperative Research Report, Chapter 3.11, p 95-104

Pettigrew N, Churchill J, Janzen C, Mangum L and 5 others (2005) The kinematic and hydrographic structure of the Gulf of Maine Coastal Current. Deep-Sea Res II 52: 2369-2391

Poppe L, Williams S, Paskevitch V (2005) U.S. Geological Survey east-coast sediment analysis: procedure, database,

Editorial responsibility: Alejandro Gallego (Contributing Editor), Aberdeen, UK and GIS data. Open-File Report DVD-ROM 2005-1001, U.S. Geological Survey, Woods Hole, MA

Pringle J (2006) Sources of variability in Gulf of Maine circulation, and the observations needed to model it. Deep-Sea Res 53:2457-2476

Ross O, Sharples J (2004) Recipe for 1-D Lagrangian tracking models in space-varying diffusivity. Limnol Oceanogr Methods 2:289-302

Runge J, Franks P, Gentleman W, Megrey B, Rose K, Werner F, Zakardjian B (2005) Diagnosis and prediction of variability in secondary production and fish recruitment processes: developments in physical-biological modeling. In: Robinson AR, Brink (eds) The sea, Vol 13. John Wiley \& Sons, New York

Schroeder W (1930) Migrations and other phases in the life history of the cod off southern New England. Bull US Bur Fish 46:1-136

Shearman K, Lentz S (2004) Observations of tidal variability on the New England shelf. J Geophys Res 109:1-16

Siegel D, Mitarai S, Costello C, Gaines S, Kendall B, Warner R, Winters K (2007) Connectivity among nearshore marine ecosystems: the stochastic nature of larval transport. Proc Natl Acad Sci (in press)

Sinclair M (1988) Marine populations: an essay on population regulation and speciation. Washington University Press, Seattle, WA

Suthers I, Franks K (1989) Inter-annual distributions of larval and pelagic juvenile cod (Gadus morhua) in southwestern Nova Scotia determined with two different gear types. Can J Fish Aquat Sci 46:591-602

Swearer S, Shima J, Hellberg M, Thorrold S and 6 others (2002) Evidence of self-recruitment in demersal marine populations. Bull Mar Sci 70:251-271

Tupper M, Boutilier RG (1995a) Size and priority at settlement determine growth and competitive success of newly settled Atlantic cod. Mar Ecol Prog Ser 118:295-300

Tupper M, Boutilier R (1995b) Effects of habitat on settlement, growth, and post-settlement survival of Atlantic cod (Gadus morhua). Can J Fish Aquat Sci 52:1834-1841

Visser AW (1997) Using random walk models to simulate the vertical distribution of particles in a turbulent water column. Mar Ecol Prog Ser 158:275-281

Werner F, Perry R, Lough R, Naimie C (1996) Trophodynamic and advective influences on Georges Bank larval cod and haddock. Deep-Sea Res II 43:1793-1822

Werner F, Quinlan J, Lough R, Lynch D (2001) Spatiallyexplicit individual based modeling of marine populations: a review of the advances in the 1990s. Sarsia 86:411-421

Wirgin I, Kovach A, Maceda L, Roy N, Waldman J, Berlinsky D (2007) Stock identification of Atlantic cod in U.S. waters using microsatellite and single nucleotide polymorphism DNA analyses. Trans Am Fish Soc 136(2): 375-391

Submitted: July 20, 2006; Accepted: April 30, 2007

Proofs received from author(s): September 28, 2007 